\title{
Transformation of Knowledge in Teaching Learning Environment Adoption of Innovative Methodology in Teaching Software Engineering
}

\author{
P. Sridhar Acharya \& P. S. Aithal \\ Srinivas Institute of Management Studies, Srinivas University, Pandeshwar, \\ Mangalore - 575 001, India \\ E-Mail: sridharaacharya@gmail.com
}

Type of the Paper: Research Case Study.

Type of Review: Peer Reviewed.

Indexed In: OpenAIRE.

DOI: http://dx.doi.org/10.5281/zenodo.846649.

Google Scholar Citation: IJCSBE

\section{How to Cite this Paper:}

Sridhar Acharya, P., Aithal, P. S. Transformation of Knowledge in Teaching Learning Environment Adoption of Innovative Methodology in Teaching Software Engineering. International Journal of Case Studies in Business, IT and Education (IJCSBE), 1(2), 22-28. DOI: http://dx.doi.org/10.5281/zenodo.846649.

International Journal of Case Studies in Business, IT and Education (IJCSBE)

A Refereed International Journal of Srinivas University, India.

(C) With Authors.

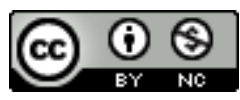

This work is licensed under a Creative Commons Attribution-Non Commercial 4.0 International License subject to proper citation to the publication source of the work.

Disclaimer: The scholarly papers as reviewed and published by the Srinivas Publications (S.P.), India are the views and opinions of their respective authors and are not the views or opinions of the S.P. The S.P. disclaims of any harm or loss caused due to the published content to any party. 


\title{
Transformation of Knowledge in Teaching Learning Environment Adoption of Innovative Methodology in Teaching Software Engineering
}

\author{
P. Sridhar Acharya \& P. S. Aithal \\ Srinivas Institute of Management Studies, Srinivas University, Pandeshwar, \\ Mangalore - 575 001, India. \\ E-Mail: sridharaacharya@gmail.com
}

\begin{abstract}
Teaching is a noble profession which requires special skills for the transformation of knowledge from teaching domain to the learning domain. This profession requires deep knowledge, dedication in teaching, encouragement, and control over the activities of the learning domain, providing the knowledge to the learning domain, teaching the discipline, behavior and smart skills as out of box teaching subjects. The teacher has to continuously upgrade himself in discharging the knowledge because whatever he has learned in his learning domain might be outdated. The Knowledge is always updating and it is the responsibility of all the teachers to update their knowledge so that they can effectively transform the same to the learning domain. The knowledge transformation in technical subject needs a rather different methodology than the traditional classroom based teaching. The subject like Software Engineering needs a different method of teaching than the traditional classroom based teaching. In this subject the learning domain should be active in looking into the various aspects of the software development. In this subject, the traditional classroom based teaching does not transform the knowledge to the learning domain because the learning domain cannot follow the subject since the domain does not have any idea about the subject. This paper explains the need for active teaching in software engineering where in the learning domain has to be active than the teaching domain. The teaching domain has to concentrate on various concepts which are supposed to be given to the learning domain and guide the learning domain how to get the knowledge, effective use of the available technology and its adoption at the right place. The objective of this paper is how to convert the learning domain into smart learning domain. This paper strongly recommends the case study based teaching and learning practice than the traditional unidirectional classroom teaching.
\end{abstract}

Keywords: Teaching domain, Learning domain, Smart learners, Methodology, Knowledge transformation.

\section{INTRODUCTION :}

Traditional classroom based teaching consists of the teacher engaging the entire hour of teaching sharing his/her knowledge or experiences. Here he/she will be talking and the students are just listening. The mode of communication here is unidirectional [1]. If some students dare to ask the question in between then the communication will be bidirectional and the class will be effective. In most of the case, the class room teaching becomes unidirectional where the teacher should speak for entire one hour [2]. The students can listen to the class for first half an hour. Since they are inactive and only listeners of the class they will not be able to understand the subject. In a day a student has to listen at least 5 to 6 hours of class where in most of the classes he/she remains inactive just listening to the teacher [3]. This method of teaching and learning practice will not serve the purpose of learning in the learning domain. Especially while teaching any technical papers the inactive involvement of the students in the class will result in nothing except a waste of time and energy of the teaching domain [4]. In this paper, the subject chosen is the software engineering. 
Software Engineering is the subject which deals with the methodology to be used in developing the commercial software in the market. The teaching domain has to prepare the learning domain to design the industrial level commercial software. The expert has to deal with customers who do not know the technicality of the system. The developer, who doesn't know the customer's requirements, cannot entrust the designer who has not got the idea of designing. Here the teaching domain has to transfer the knowledge of a project manager to the learning domain wherein the learning domain does not have any foundation about the topic. The subject gives importance to the method of collecting requirements, planning, design, the usage of various mathematical logics, usage of computer software techniques, testing methodologies and so on [5]. Software engineering not only concentrates on the development of software but also the testing, client side installation, post installation systematic operation, maintenance [6]. It is very much important to study the concepts of Software Engineering while handling any projects. Entire software development and maintenance activity depend on the software engineering concepts. So it is very much important for the computer application students to thoroughly study the software engineering concepts.

Various activities involved in developing industrial level software are [7]:

- Feasibility study

- Collection of Requirements.

- Analyses of those requirements

- Modularization and Design

- Coding

- Modularized testing

- Integration and system testing

- Implementation and user training

- Maintenance

These activities should be considered with care failing which the software design will not be useful in the market. Unless one has the hands on work experience under any expert developer, he or she will not be able to get the desired output. Unless one understands the theory of software engineering he or she can not develop the project. Unless he or she has the knowledge about the practical aspects of the project he or she cannot understand the theory of software engineering. The students neither have the idea about the development of software nor have the required knowledge on the subject [8]. Teachers handling this paper in undergraduate program find it very difficult to teach. The teachers have to concentrate only on the theory as per the syllabus given by the university to finish the syllabus in time. Since the students have no idea about this paper they find it very difficult to understand. In this case the teacher has to take several examples of software engineering to teach the above activities to the students. But if the teacher does so he/she will not be getting time to finish the syllabus in time. This makes the students totally unaware of the subject until they get the practical exposure [9]. As per the observation of the teacher the students start actually learning this paper during their project work because they have to use the same theory for developing the project. Entire software engineering theory which they learn in the entire semester without the practical knowledge is of no use. The only method of teaching the above subject is to convert the class room into an active classroom where the teacher is simply giving the various tasks to the students on above activities and simply helping them in finding the solution. The students should search for the solution by themselves and solve the above activities [10].

\section{THE OBJECTIVES :}

The objective of this paper is to propose a model to make an active classroom where the students themselves work on the various activities related to the software engineering. The objective is also to make the students experience the various activities involved in the software engineering than mugging up the concepts without understanding. This creates a very strong learning environment among the students. 


\section{METHODOLOGY :}

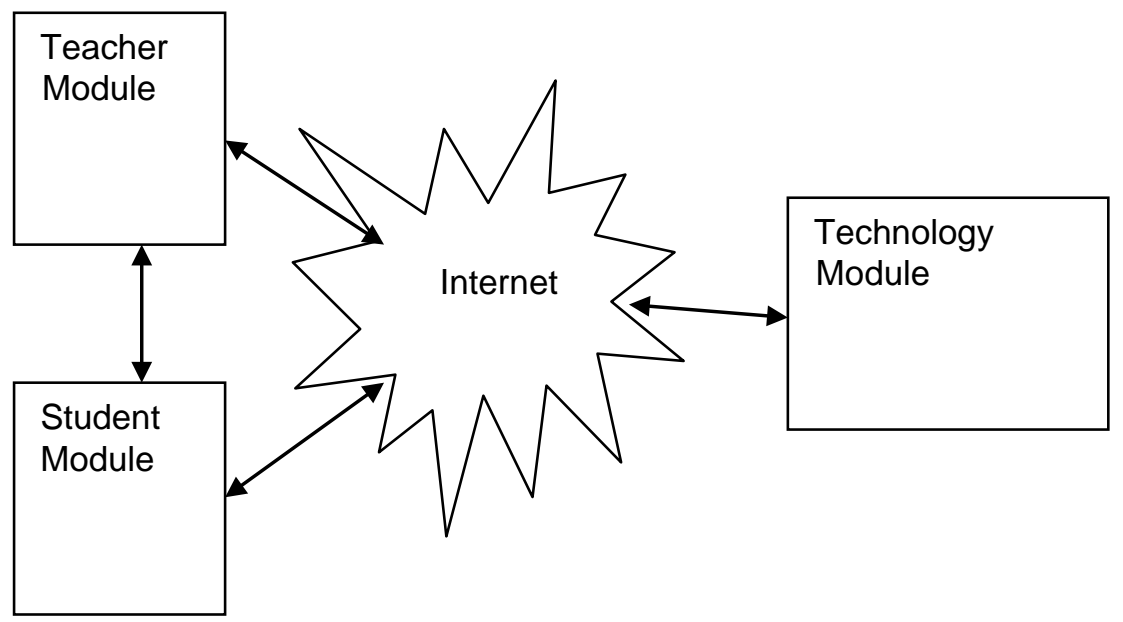

Figure 1: The proposed module of active teaching learning model.

The proposed model deals with three modules namely

1. Teacher module.

2. Student module.

3. Technology module.

The diagrammatic representation of the model is as shown in figure 1 . The functionalities of the three modules are as explained below.

\subsection{Teacher module}

Teacher module is quite different from the regular class room teaching. Here the teacher module is integrated with the client server technology. Here the teacher is given a login ID. In this login, the teacher has a responsibility of designing practical cases for every activity of the software engineering. (the activities are mentioned in the introduction). The teacher should prepare as many cases relevant to the activity as possible. These cases have to be uploaded to the server inside the teacher's portal. The teacher should also upload the necessary materials using which all the cases can be solved. The teacher will be only guiding the students in solving the modules inside the classroom. The teacher is not teaching anything in the class which may create an inactive environment inside the class. The teacher is just monitoring the students who are actively participating either individually or in a group solving the cases given. In the case of necessity, the teacher can guide the students to solve the case inside the classroom. This creates an active classroom. The performance of the student in solving the case is uploaded in the server for the evaluation. The teacher will go through the performance of each student in the server and give the marks to respective students.

\subsection{Student Module}

In this module, every student is connected to the server through the Internet. The student is given a Tablet to use inside the class. The student gets the access to the teacher's portal where in the teacher has already uploaded the related case for the analysis. The teacher is just an observer and gives the deadline to finish the case analysis. The student can discuss with his fellow friends, go to the server in search of the related material or through the server he can go even to any related site to get the material. The student cannot go to any other irrelevant site or social media site. The productivity of the student decreases with the social media and other irrelevant sites. The student has the responsibility to submit the given task before the scheduled time. The student can seek the help of the teacher only in case of emergency, where in he/she is not in a position to search and get the information for the case. This situation exists only in the beginning stage where the student gets an idea to search the necessary information. This method makes the student to actively participate in studies. The student will continuously think about the subject until he/she finishes the given assignment. The knowledge thus obtained will be permanent because it is the knowledge from experience and the student puts a lot of effort to gain it. In case of traditional teaching system the 
student pretends to be listening to the subject. But he/she is not. In almost all the cases the students prepare for examination only one week before the examination. This results in failure.

\subsection{Technology module}

The technology module places a very important role in this case. Here the organization should set up a higher end server with the necessary software developed. This module requires a high speed with higher bandwidth since all the students and the teachers are connected to the same server. The server should have a strong firewall to block the unwanted sites. The server should block even the social media sites which divert the attention of the students away from the studies. The technology module provides a Tablet to all the teachers and students. The students and teachers use this tablet to connect to the server. The tablet should be designed in such a way that it cannot be used for other social activities, no public Internet connection. The tablet is used to download the related cases for solution and all the supporting study materials for the study. This module should keep track of the performance of the student and the continuous monitoring report should be sent to the parents.

\section{ANALYSIS :}

The various aspects of the proposed model is discussed below. Here mainly what are the advantages of having this type of active teaching and learning process is discussed. Further various benefits of having this model is also discussed from the point of view of teacher, learner, industry. The various constraints of having this model is also discussed and finally the drawbacks of adopting this model is also discussed. Such methodology of analysis is called ABCD listing [11-23].

\subsection{Advantages}

There are many advantages of adopting this model in the classroom like

- The students will be active throughout inside the classroom because they are working instead of listening.

- The students will be alert because their work is totally time bound. They should finish their work within the given time as to go to next lectures.

- The understanding level of the students increases. This model helps the learning domain to understand instead of by hart.

- More and more practical exposure in the form of case study is given to the students. This helps the students ready to face the industries without any pre training.

\subsection{Benefits}

This model, if used in the teaching and learning domain has several benefits like

- When the students get the real projects in the market, they don't find any difficulties since they had already done much case analysis related to the project development.

- Teachers can keep themselves busy in uploading the new cases related to Software Engineering. This makes the teacher also to upgrade his knowledge instead of hanging on the same old syllabus and book.

- Both the teachers and students update their knowledge. The knowledge will be updated and market adaptable ones in lien of obsolete technology.

\subsection{Constraints}

Implementing this model has several challenges or constraints like

- The teaching domain should be tech savvy. Since the subject belongs to the computer technology all the teachers will be tech savvy only. But if there is any teacher who is not tech savvy then he /she will find this model very difficult.

- Fast Internet with higher bandwidth is required as Internet is the backbone of the active classroom.

- Organization should invest huge money on setting up the technology module.

\subsection{Drawback}

Several drawbacks will be there in using this model

- Students acceptance in changing themselves into active students

- Syllabus to time limit

- Bringing this type of awareness in the education field 


\section{CONCLUSIONS :}

It is said that no one is intelligent as well as no one is dull. It is the involvement of each individual in studies which make him either intelligent or dull. The more one involves himself in any activity the more knowledge he will get. Thus to gain a deeper knowledge in the subject one should actively involve. This active involvement gives one a good knowledge and good hold on the subject. In all the cases the active involvement of both teaching and learning modules are essential. Normally due to several reasons, the classroom teaching makes the students to be a passive listener. If the same class room is converted into an active classroom by adopting the above model then the system would get all the qualified and learned scholars in the country. In the conclusion, the following points are suggested.

- Instead of monotonous teaching, the practical based case study is required.

- Students must be given the time limit to complete the exercise.

- Teachers should just guide the students instead of explaining the subject.

- Teachers should create more and more cases in teaching the subject.

- A hi-tech network based client server technology is very essential.

\section{REFERENCES :}

[1] Scerbo W. M. Warm J.S. Dember W.N. and Grasha A.E. (1992). The role of time and cueing in a college lecture. Contemporary Educational Psychology, 17(4), 312-328.

[2] Hopson, M. H., Simms, R. L. \& Knezek, G. A. (2002), Using a technology-enriched environment to improve higher-order thinking skills, Journal of Research on Technology in Education, 34 (2): 109-119, doi:10.1080/15391523.2001.10782338.

[3] Eisenman, Gordon, Susan Edwards, and Carey Anne Cushman (2015). Bringing Reality To Classroom Management in Teacher Education. Professional Educator. Academic Search Complete. 39 (1), 1-12.

[4] Soheili, Fariba; Alizadeh, Hamid; Murphy, Jason M.; Bajestani, Hossein Salimi; Ferguson, Eva Dreikurs (2015). Teachers As Leaders: The Impact Of Adler-Dreikurs Classroom Management Techniques On Students' Perceptions Of The Classroom Environment And On Academic Achievement. Journal of Individual Psychology. 71 (4), 440-461.

[5] Pankaj Jalote (2008). A Concise Introduction to Software Engineering Springer Verlag London Publication, pp. 1-8, ISBN-978-1-84800-301-9, DOI 10.1007/ 978-1-84800-302-6.

[6] Jeffrey C. Carver, Neil P. Chue Hong, George K. Thiruvathukal (2017). Software Engineering for Science, CRC Publication, pp. (1-12), ISBN-13:978-1-4987-4385-3.

[7] Anuradha A. Puntambekar, (2007). Software Engineering, First Edition pp, (2.1-2.44) Technical Publications Pune, ISBN 81-8431-183-4.

[8] John W. Horch (1995). Two Orientations On How To Work With Objects. In: IEEE Software. 12(2), 117-118.

[9] Xiao He (2007). A metamodel for the notation of graphical modeling languages. In: Computer Software and Applications Conference, 2007. COMPSAC 2007 - Vol. 1. 31st Annual International, 1(24-27), 219-224.

[10] Lughofer, E. (2012), Hybrid Active Learning (HAL) for Reducing the Annotation Efforts of Operators in Classification Systems. Pattern Recognition, 45(2), 884-896.

[11] Aithal, P. S. (2017). Comparative Study of Various Research Indices used to measure quality of Research Publications. International Journal of Applied and Advanced Scientific Research (IJAASR), 2(1), 81-89. DOI : http://doi.org/10.5281/zenodo.569763.

[12] Sridhar Acharya P. \& Aithal P. S., (2016). Concepts of Ideal Electric Energy System for production, distribution and utilization. International Journal of Management, IT and Engineering (IJMIE), 6(1), 367-379. 
[13] Padmanabha Shenoy, and Aithal P. S., (2016). A Study on History of Paper and possible Paper Free World. International Journal of Management, IT and Engineering (IJMIE), 6(1), 337-355.

[14] Aithal, P. S. (2015). Comparative Study on MBA Programmes in Private \& Public Universities - A case study of MBA programme plan of Srinivas University, International Journal of Management Sciences and Business Research (IJMSBR), 4(12), 106-122.

[15] Aithal P. S., \& Shubhrajyotsna Aithal (2016). Impact of On-line Education on Higher Education System. International Journal of Engineering Research and Modern Education (IJERME), 1(1), 225-235.

[16] Aithal P. S., and Suresh Kumar P. M., (2016). Analysis of Choice Based Credit System in Higher Education. International Journal of Engineering Research and Modern Education (IJERME), 1(1), 278-284.

[17] Varun Shenoy and Aithal P. S., (2016). Changing Approaches in Campus Placements - A new futuristic Model, International Journal of Scientific Research and Modern Education (IJSRME), 1(1), 766 - 776 .

[18] Aithal, P. S. \& Shubhrajyotsna Aithal (2016). Ekalavya Model of Higher Education - an Innovation of IBM's Big Data University. International Journal of Current Research and Modern Education (IJCRME), 1(2), 190-205. DOI: http://dx.doi.org/10.5281/zenodo.198704.

[19] Aithal, P. S. \& Shubhrajyotsna Aithal, (2016). A New Model for Commercialization of Nanotechnology Products and Services. International Journal of Computational Research and Development, 1(1), 84-93. DOI : http://doi.org/10.5281/zenodo.163536.

[20] Aithal, P. S. \& Suresh Kumar, P. M. (2017). Challenges and Opportunities for Research \& Publications in Higher Education. International Journal of Scientific Research and Modern Education (IJSRME), 2(1), 42-49. DOI: http://dx.doi.org/10.5281/zenodo.400619.

[21] Vaikunth Pai T. \& Aithal, P. S., (2017). Cloud Computing Security Issues - Challenges and Opportunities. International Journal of Management, Technology, and Social Sciences (IJMTS), 1(1), 33-42. DOI: http://dx.doi.org/10.5281/zenodo.569920.

[22] Krishna Prasad, K. and Aithal, P. S. (2017). A Study on Enhancing Mobile Banking Services using Location based Authentication. International Journal of Management, Technology, and Social Sciences (IJMTS), 1(1), 48-60. DOI: http://doi.org/10.5281/zenodo.583230.

[23] Aithal, P. S. (2017). ABCD Analysis of Recently Announced New Research Indices. International Journal of Management, Technology, and Social Sciences (IJMTS), 1(1), 65-76. DOI: http://doi.org/10.5281/zenodo.583644.

[24] Sridhar Acharya, P. \& Aithal, P. S. (2017). Increasing the Efficiency in Renewable EnergyChallenges and Solutions for Rural India. International Journal of Applied Engineering and Management Letters (IJAEML), 1(1), 1-5. DOI: http://dx.doi.org/10.5281/zenodo.810341. 